\title{
Prevalence of Color Vision Deficiency among Medical Students in KFU- SA (2014 - 2015)
}

\author{
Shoaa Mohammed Alharfi ${ }^{1}$, Gofran Mohammed Al-Braheem ${ }^{1}$, Fatimah Ali Al-Khamis ${ }^{1}$,Fatimah Salman \\ Al-Ramadhan ${ }^{1}$, Mariam Ali Al-Odail ${ }^{1}$, Sayed Ibrahim Ali ${ }^{2}$, Aliya Elamin Mohammed ${ }^{2}$ \\ 1, 2, 3, 4, 5 Medical Students at King Faisal University, College of Medicine, Saudi Arabia \\ ${ }^{6,7}$ King Faisal University, College of Medicine, Saudi Arabia
}

\begin{abstract}
Red-green color deficiency is a disability in which a person cannot distinguish between red from green, and it's one of the diseases that occur mostly in males since it is an X-linked disorder, although it can also occur in females. It can be acquired due to many vision problems. This cross-sectional study was conducted to determine the prevalence of color deficiency among medical students in King Faisal University (KFU) by using questionnaires and Ishihara charts. The study showed that the prevalence of color vision deficiency among medical students was $2.7 \%(n=9)$ among the study sample (5 out of 194 females (2.57\%) and 4 out of 129 males (3.1\%) were found to have red-green color vision deficiency (CVD). Among the students who had CVD there were 2 of them had other vision problems, and the remaining 7 were not suffering from any vision problems. In addition, 22.2\% of them had a family history of CVD and $77.78 \%$ did not had. Chi-square test $(P$ value $=0.36)$ shows that there is no significant relationship between color vision deficiency and having family history of this disorder. The study proved that the CVD among medical students in KFU is noticeable. Since this disorder can affect their performance in the future, they should be made aware of their condition and be guided to consider this problem while practicing their jobs. Based on these, findings it is recommended that further studies are needed using a bigger sample size using the same population to confirm or refuse the initial findings from this study.
\end{abstract}

Keywords: Prevalence, color vision, medical students

\section{Introduction}

Color vision deficiency (CVD), is the lack of ability to distinguish between certain colors. John Dalton is the first person to write a scientific paper about CVD, who himself was color deficient, that's why CVD was named 'Daltonism' previously.[1] The cause in most cases are genetic defect but might also be acquired damage affecting the eye, nerve, or brain or use of certain chemicals.[2] It is of course different in different races and regions of the world.[3,] The 3types of CVD are Tritan (blue) Duetan (green), and Protan (red). Congenital red-green Color vision deficiency is an $\mathrm{X}$ linked recessive disease, as a result, it occurs almost exclusively in males, while the blue type is acquired. [4] Some of the color deficient people aren't able to recognize any color and see the world as gray.[5]

Health professionals suffering from CVD have difficulty detecting physical signs, body color changes (pallor, cyanosis, jaundice), skin rashes and erythematic, Stage I pressure ulcers, blood or bile in urine, feces, sputum, vomit, melaena, mouth and throat conditions, test strips, color coded medications, charts, slides, prints, and color sensitive monitors.[6] Therefore, the patients' safety is in danger if CVD is not tested regularly. [7] Unfortunately, There are many doctors who do not know the severity of their color deficiency, and a few of them don't even know about their condition.[8] The medical students must be aware of their deficiencies and know their severity so that they can take special care in clinical practice. [9]

This study will be conducted to study the prevalence of redgreen color vision deficiency among medical students in King Faisal University by using questionnaires that will be filled by the students directly or online and by using Ishihara charts.

\section{Material and Methods}

Study design: A cross-sectional study was conducted at the college of medicine in King Faisal university [Al-Ahsa] eastern region of Saudi Arabia; the aim of the study is to investigate the prevalence of color vision deficiency (CVD) among medical students

- Study subjects: Medical students (males and females) of all batches, aged 18-25. The total number of the students is 1147 , but the number of respondants was 323 students.

- Materials: For this study, 2 tools were used to investigate the problem:

\section{1- Questionnaire}

Consisted of 17 different questions Consisted of 17 different questions asking about the biographical data, family history of color vision deficiency, drugs the volunteer on, optical diseases, any health problems in general, exposure to any chemical, and having bad trauma on the head or the eyes.

\section{2- Ishihara's chart}

This chart was made in Japan,and it consisted of 38 plates called Ishihara plates, each of which contains a circle of dots appearing randomized in color and size. These dots form a number or shape clearly visible to those with normal color vision, and invisible, or difficult to see, to those with color vision deficiency.

Method: First, the students were asked to fill the questionnaire, then, to read the plates on the Ishihara's chart. 


\section{International Journal of Science and Research (IJSR) \\ ISSN (Online): 2319-7064}

Index Copernicus Value (2013): 6.14 | Impact Factor (2015): 6.391

Also the students had to choose whether to fill a printed or an online questionnaire. The collected data were tabulated and statistically analyzed using SPSS version 22. Chi-square test was applied to determine whether there is a significant difference between color vision deficiency (CVD) and having a family history of CVD and other vision problems.

\section{Results}

Three hundred and twenty three Saudi medical students (1824 years old) from KFU, college of medicine participated in this cross sectional study. Descriptive statistics of the study variables are shown in the following tables and figures.

1) Prevalence of color vision deficiency among the participants:

Table (1) and figure (1) show that $2.7 \%(n=9)$ of the sample $(\mathrm{n}=323)$ was red-green color deficient.

Table(2) as well asFigure (2) shows the prevalence among males and females separately. Among all females $(n=194), 5$ were found to have red-green CVD (2.57\%), while 189 didn't appear to have red-green CVD. In addition, among males $(n=129) 4$ were found to have redgreen CVD(3.1\%), and the remaining 125 weren't suffering from it. Blue bars represent students with no color vision deficiency (CVD), while the orange ones represent the students with CVD.

2) Relationship between CVD and problems in vision: Figure (3) Shows the relationship between the presence of CVD and the presence of other vision problems. $22 \%$ $(n=2)$ of the affected students have other vision problems, and $78 \%(\mathrm{n}=7)$ of them do not have any other vision problems.

3) Relationship of CVD students to family history:

Figure (4) Shows the relation of students with red-green color vision deficiency to family history. Which reveals that among the students who have red-green CVD, 22\% of them have family history of CVD and $78 \%$ without family history. Chi-square test $(\mathrm{P}$ value $=0.36$, CI 95\%) shows that there is no significant relationship between color vision deficiency and having family history of the disease.

\section{Discussion}

Three hundred and twenty three (324) medical students (1824 years old), were participated in this cross-sectional study. Descriptive statistics of the study variables were done. The importance of this study lies in the fact that, it will establish a base line for screening CVD among the students for comparison in the future studies.

This study showed that the prevalence of red-green color vision deficiency among medical students of King Faisal University, constitute $2.7 \%(n=9)$ of the participants.

In this study the prevalence of CVD is higher among male students comparing to the female students, which agreed with the findings of a cross sectional study examined 1853 Iranians with age 10-25 years old in 2010, the results indicated that $0.93 \%$ females and $2.56 \%$ males were color deficient. ${ }^{[6]}$ The possible explanation why CVD is higher in male than female is that CVD is a common X-linked genetic disorder. taht swohs yduts sihT (3.1\%) of the male medical students in KFU found to have CVD, which was almost similar to the percentage $(2.93 \%)$ that had been found after CVD screening among Arab boys from Riyadh. ${ }^{[10]}$ This similarity in the results is due to the fact that both studies were conducted on Saudi subjects which means they come from the same ethnicity. In contrast, the result in this study found to be different from what had recorded in Erbil City in Iraq, which was about $(8.46 \%)$ in men. ${ }^{[11]}$ Erbil people had a different race, since they are Kurdish, not Arab. Therefore, the difference in the prevalence of CVD can be attributed to the genetic differences between the races. Another study was carried out among the medical and dental male students of Nepal Medical College and Teaching Hospital $(n=215)$ it was noted that among the study population 12 were color deficient $(5.58 \%) .{ }^{[12]}$ The differences in the percentage of the results between the two researches may be due to the huge different in the sample size and ethnicity.

The prevalence of red-green CVD among female medical students in this research was $(2.5 \%)$, which found to be greater than the percentage of European Caucasians women (about $0.4 \%) .^{[13]}$ The higher percentage of Saudi females with CVD may be due to the Saudi habits, which is performing consanguineous marriage, would contribute in having a high incidence of this disorder, even among females.

This study showed that among the sample, the students with family history of CVD were classified as having hereditary CVD $(0.61 \%)$, and those who did not confirmed any family history were classified as acquired category $(2.16 \%)$. One study conducted in Shahroud in Iran showed that of the 2,157 participants, $(9.3 \%)$ were hereditary and $(20.2 \%)$ were acquired. ${ }^{[13]}$ The high percentage of acquired CVD could be due to changes associated with age, medical and ocular conditions, and differences in race and environment. In addition, because that disorder is usually unnoticed, they might have familial defects but they are not aware of it.

\section{Conclusion and Recommendation}

This study showed that the percentage of students with redgreen color vision deficiency is $(2.7 \%)$ which is a considerable number, this mean that CVD is noticeable disorder in KFU, college of medicine. It is more common among male because it is an X-linked disorder. Color is often used in medicine, which makes normal color vision very important for medical students. This study can raise the awareness about color vision deficiency, also, it indicate the need of screening for CVD among medical students and doctors especially because it is unnoticeable disorder. Unawareness of having CVD can put the patients' safety in danger. This study should be taking in consider because medical students and doctors with known CVD could choose the right specialties for themselves.

We recommended that, this study should be conducted among all the medical students because each one of them must be aware about his/her condition concerning CVD.

\section{Volume 5 Issue 6, June 2016} www.ijsr.net 


\section{International Journal of Science and Research (IJSR) \\ ISSN (Online): 2319-7064}

Index Copernicus Value (2013): 6.14 | Impact Factor (2015): 6.391

Table 1: Prevalence of color vision deficiency among the participants

\begin{tabular}{|c|c|c|}
\hline & $\begin{array}{c}\text { Number of } \\
\text { students }\end{array}$ & Percentage \% \\
\hline $\begin{array}{c}\text { Normal students, } \\
\text { with no CVD }\end{array}$ & 314 & $97.3 \%$ \\
\hline Students with CVD & 9 & $2.7 \%$ \\
\hline
\end{tabular}

Table 2: Prevalence of red-green color vision deficiency among males and females

\begin{tabular}{|c|c|c|c|}
\hline & $\begin{array}{c}\text { Sample } \\
\text { size }\end{array}$ & Females & Males \\
\hline Total & 323 & 194 & 129 \\
\hline $\begin{array}{c}\text { Normal students, with } \\
\text { no CVD }\end{array}$ & 314 & 189 & 125 \\
\hline students with CVD & 9 & 5 & 4 \\
\hline $\begin{array}{c}\text { Percentage of students } \\
\text { with CVD }\end{array}$ & $2.7 \%$ & $2.57 \%$ & $3.1 \%$ \\
\hline
\end{tabular}

TOTAL NORMAL AND ABNORMAL

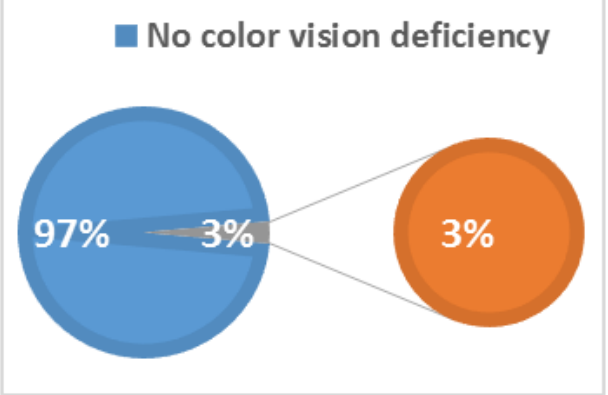

Figure 1: Prevalence of color vision deficiency among the participant

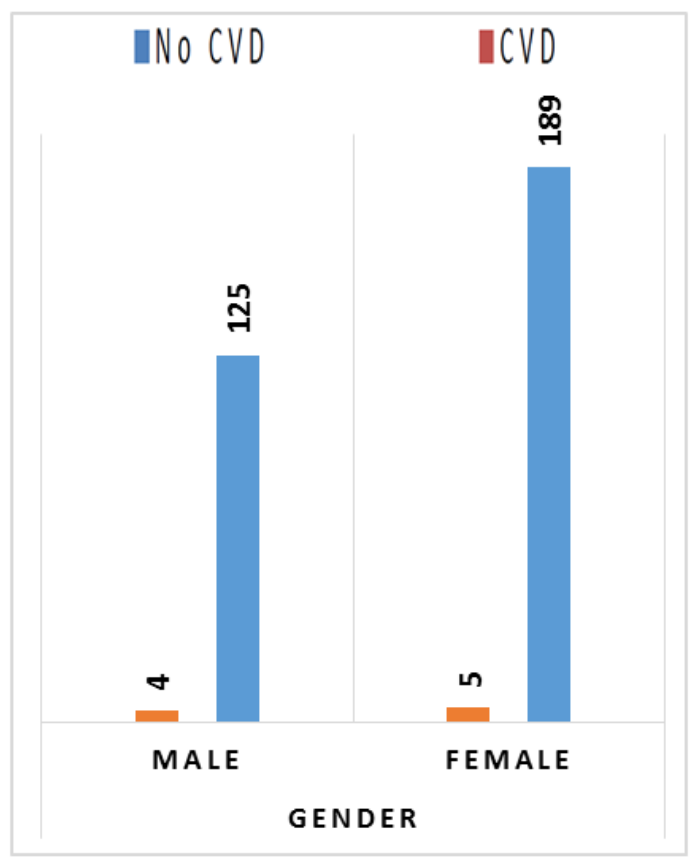

Figure 2: Prevalence of color vision deficiency among males and females.
Vision Problems and Color Vision Deficiency

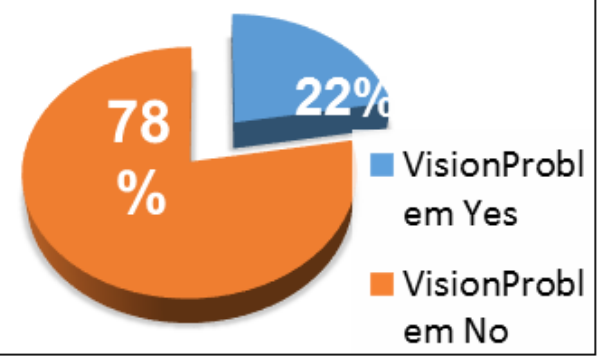

Figure 3: The relationship between vision problems and color vision deficiency.

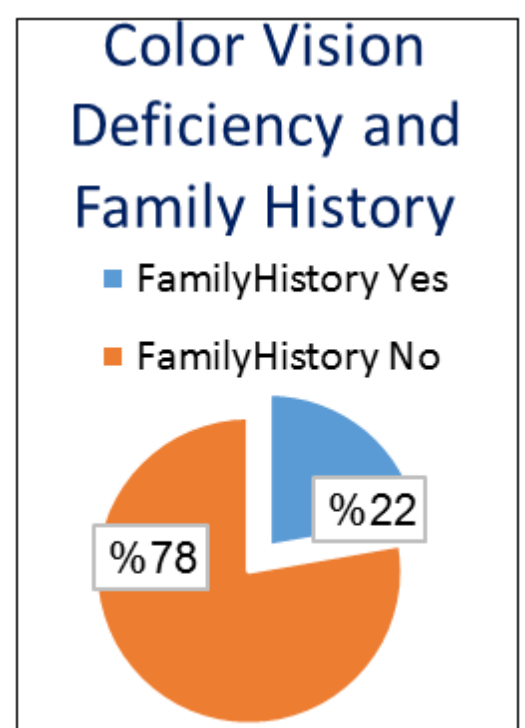

Figure 4: The relationship between color vision deficiency and family history

\section{References}

[1] Sieving PA, Caruso RC. Retinitis pigmentosa and related disorders. In: Yanoff $\mathrm{M}$, Duker JS, eds. Ophthalmology. 3rd ed. St. Louis, MO: Mosby Elsevier; 2008:chap 6.10

[2] Arthur C. Guyton, John E. Hall. guyton and hall textbook of medical physiology. 12th ed. Philadelphia: Saunders, an imprint of Elsevier Inc; 2011.

[3] Hossain MI1, Nahar L, Dad MS, Islam MF, Uddin MM. Prevalence of colour blindness among the first year medical \& dental students of Mymensingh Medical College, Bangladesh. Mymensingh Med J. 2013 Oct;22(4):661-4

[4] Irfan Ahmed Mughal, Liaqat Ali*, Nasir Aziz**, Khalid Mehmood, Naila Afzal colour vision deficiency (cvd) in medical students pak J Physiol 2013;9(1)

[5] Niroula, Saba. The incidence of colour blindness among some school children of Pokhara, West Nepal. Nepal Med Coll J 2010;12(1):48-50.

[6] 13-Birch J, Opt Soc Am A Opt Image Sci Vis, Worldwide prevalence of red-green color deficiency, Mar 2012, 1;29(3):313-20. 
[7] Nathans J, Piantanida TP, Eddy RL, Shows TB, Hogness DS.Molecular Denetics of Inherited Variation in Human ColorVision. Science 1986;232:203-10.

[8] Ebi Peter Osuobeni. Prevalence of congenital red-green color vision defects in Arab boys from Riyadh, Saudi Arabia. 1996 Dec;3(3):167-70.

[9] Khalaj M, Barikani A, Mohammad M. Prevalence of Color Vision Deficiency in Qazvin. ZJRMS 2014; 16 (1): $91-93$

[10] Dalton J. Extraordinary facts relating to the vision of colors: with observations. Memoirs of the Literary and Philosophical Society of Manchester 1798;5:28-45.

[11] T Pramanik, MT Sherpa and R Shrestha. Color vison deficieny among medical students: an unnoticed problem. Nepal Med Coll.J 2010: 122: 81-83.

[12] Prevalence of Color Vision Deficiency in Qazvin Mohammad Khalaj, ${ }^{* P 1 P}$ Ameneh Barikani,P2P Mozhgan MohammadiP 3- ZJRMS 2014; 16 (1): 91-93

[13] Hossein Dargahi, Nahid Einollahi, and Nasrin Dashti, Color Blindness Defect and Medical Laboratory Technologists: Unnoticed Problems and the Care for Screening in Tehran, Iran 20 Jun. 2009. 11

[14] Karim J. Karim, Mohammed A. Saleem, Prevalence of Congenital Red-Green Color Vision Defects among Various Ethnic Groups of Students in Erbil City, Jordan Journal of Biological Sciences, September 2013, Volume 6, Number 3, pp. 235 - 238. 